\title{
Notch-1 inhibition reduces proliferation and promotes osteogenic differentiation of bone marrow mesenchymal stem cells
}

\author{
YING HE $^{1}$ and LIJIN ZOU ${ }^{2}$ \\ ${ }^{1}$ Department of Infectious Diseases; ${ }^{2}$ Burn Center, The First Affiliated Hospital \\ of Nanchang University, Nanchang, Jiangxi 330006, P.R. China
}

Received August 17, 2018; Accepted June 5, 2019

DOI: $10.3892 /$ etm.2019.7765

\begin{abstract}
Low differentiation and high proliferation rates are critical factors affecting bone marrow mesenchymal stem cell (BMSC) tumorigenesis. The present study aimed to investigate the role of the Notch signaling pathway in BMSC proliferation and osteogenic differentiation. Mouse BMSCs were divided into control, vector, Notch1-small interfering (si)RNA, $\gamma$-secretase inhibitor, and Notch1-siRNA $+\gamma$-secretase inhibitor groups. The siRNA-Notch1, $\gamma$-secretase inhibitor, and Notch1-siRNA $+\gamma$-secretase inhibitor groups were treated with Notch1 siRNA and/or $\gamma$-secretase inhibitor. Following treatment, cell proliferation was evaluated using a Cell Counting Kit-8. Tumor-related factors, including transforming growth factor (TGF)- $\beta 1, \mathrm{c}-\mathrm{Myc}$ and $\mathrm{p} 53$, were detected by reverse transcription-quantitative polymerase chain reaction and western blot analyses. BMSC osteogenic differentiation was induced and the cells were stained with alizarin red at 14 and 21 days. Alkaline phosphatase (AKP) activity was also evaluated. The siRNA-Notch1 and $\gamma$-secretase inhibitor both reduced BMSC proliferation and the expression of TGF- $\beta 1$ and c-Myc and increased the expression of p53. Following the induction of osteogenesis and staining with alizarin red, the level of AKP was significantly higher in cells in the siRNA-Notch1 and $\gamma$-secretase inhibitor groups compared with that in the control group. It was found that Notch1 inhibition reduced proliferation and promoted the osteogenic differentiation of BMSCs.
\end{abstract}

\section{Introduction}

Osteosarcoma is histologically defined as abnormal osteoid arising from malignant spindle tumor cells. This condition may arise from bone marrow mesenchymal stem cells (BMSC), a type of pluripotent stem cell, during their differentiation into

Correspondence to: Dr Lijin Zou, Burn Center, The First Affiliated Hospital of Nanchang University, 17 Yongwai Zheng Street, Nanchang, Jiangxi 330006, P.R. China

E-mail: zoulijin11@163.com

Key words: bone marrow mesenchymal stem cells, Notch signaling pathway, cancer stem cells, transforming growth factor- $\beta 1$ mature osteoblasts (1). BMSCs differentiate into a variety of mature cells, including bone cells (osteoclasts and osteoblasts), chondrocytes and adipocytes, and possess the ability to renew, differentiate and be involved in angiogenesis (2). Due to the unique properties of BMSCs, including easy isolation, in vitro amplification, differentiation and immune tolerance (3), this cell type has therapeutic potential in vascularization and tissue repair. Therefore, BMSCs are widely used in cell therapy clinical trials $(4,5)$ and pre-clinical studies $(6,7)$. In addition, the prospect of applications in alternative therapy is broad. However, abnormal BMSC differentiation and uncontrolled proliferation may lead to the development of osteosarcoma (8).

The Notch signaling pathway serves an important role in the regulation of cell fate during embryonic and postnatal development and is involved in regulating the differentiation of adult stem cells $(9,10)$. It is a conserved cell signaling mechanism found in most multicellular organisms (11). Once a Notch receptor binds with ligands on the surface of adjacent cells, the intracellular domain dislocates from the cell membrane, transports into the nucleus and interacts with downstream molecules to regulate the Notch cascade (12). The Notch pathway also mediates intercellular signaling, thus affecting endothelial cell proliferation, survival and differentiation (13). The Notch signaling pathway serves a vital role in angiogenesis, and changes in the pathway lead to the abnormal development of blood vessels (13). Previous studies have reported that the Notch signaling pathway serves an important role in stem cell proliferation and angiogenesis (14).

However, whether this pathway is involved in the malignant transformation of BMSCs remains to be elucidated. The present study aimed to investigate how the Notch signaling pathway influences BMSC differentiation and malignant transformation. The study also aimed to provide a theoretical basis for understanding the pathophysiologic mechanism of osteosarcoma in detail and provide a foundation for the eventual incorporation of MSCs into tissue engineering and clinical application.

\section{Materials and methods}

Cell culture. A BMSC cell line was gifted by Professor Yang Xiang (Human Aging Research Institute, Nanchang University, Nanchang, China) and cultured in GlutaMAXTM-1 Dulbecco's modified Eagle's medium (DMEM; cat. no. 1859228; Gibco; 
Thermo Fisher Scientific, Inc.) supplemented with $10 \%$ fetal bovine serum (FBS; Hyclone; GE Healthcare Life Sciences) in $5 \% \mathrm{CO}_{2}$ at $37^{\circ} \mathrm{C}$. The cells were divided into the following five groups:Control, vector, small interfering RNA(siRNA)-Notch1, $\gamma$-secretase inhibitor (DAPT; Selleck Chemicals), and siRNA Notch $1+\gamma$-secretase inhibitor groups. Cells $\left(5 \times 10^{3} /\right.$ well $)$ at $80 \%$ confluence were transfected with $1 \mu \mathrm{g} / \mathrm{ml}$ empty vector (F: 5-CCUACGCCACCAAUUUCGU-3', R: 5-ACGAAA UUGGUGGCGUAGG-3) or Notch1-siRNA (F: 5-GCACGC GGAUUAAUUUGCA-3', R: 5'-UGCAAAUUAAUCCGC GUGC-3'; GenePharma Co. Ltd.) using Lipofectamine ${ }^{\circledR} 3000$ (Invitrogen; Thermo Fisher Scientific, Inc.). After 6 h, the medium was replaced with fresh DMEM containing $10 \%$ FBS and cultured in a $5 \% \mathrm{CO}_{2}$ incubator at $37^{\circ} \mathrm{C}$ for $48 \mathrm{~h}$. The cells $\left(5 \times 10^{3} /\right.$ well) were then cultured in normal medium and treated with $5 \mu \mathrm{M}$ DAPT for an additional $24 \mathrm{~h}$. Cell proliferation was confirmed and tumor-related proteins were detected.

Cell counting Kit- 8 (CCK-8) assay. The cells $\left(3 \times 10^{3} / \mathrm{ml}\right)$ were seeded in 96-well plates. Following experimental treatment, $10 \mu 1$ DMEM with CCK-8 (cat. no. KGA317; Jiangsu KeyGen Biotech Co., Ltd., Nanjing, China) was added. The cells were incubated for an additional $4 \mathrm{~h}$ in a $\mathrm{CO}_{2}$. incubator at $37^{\circ} \mathrm{C}$ and the absorbance at $560 \mathrm{~nm}$ was recorded using a microplate reader (Thermo Fisher Scientific, Inc.). The optical density (OD) values measured represented cell viability.

Reverse transcription-quantitative polymerase chain reaction $(R T-q P C R)$ analysis. Total mRNA was extracted using a TRIzol assay kit (Baosheng Science \& Technology Innovation Co, Ltd.). The mRNA was transcribed into cDNA using a TakaraReverse Transcription kit according to the manufacturer's protocol (cat. no. RR037A; Takara Biotechnology Co., Ltd.). RT-qPCR analysis was performed to detect the expression level of target genes using SYBR Green. The amplification reactions were performed with initial denaturation at $95^{\circ} \mathrm{C}$ for $10 \mathrm{~min}$, followed by 38 cycles of two-step PCR at $95^{\circ} \mathrm{C}$ for $17 \mathrm{sec}$ and $61^{\circ} \mathrm{C}$ for $1 \mathrm{~min}$. The levels of Notch1, TGF- $\beta 1$, c-Myc and p53 were normalized to those of GAPDH using the $2^{-\Delta \Delta \mathrm{Cq}}$ method (15). The primers were designed by Sangon Biotech and were as follows: Notch1, forward (F) 5-CGAAGT GGACATTGACGAGT-3' and Notch1, reverse (R) 5-GGC ATAAGCAGAGGTAGGAGT-3'; TGF- $\beta 1$, F 5-CCTGTC CAAACTAAGGCTCG-3' and TGF- $\beta 1$, R 5-ATGGCGTTG TTGCGGTC-3'; c-Myc, F 5-GCTCGCCCAAATCCTGT-3' and c-Myc, R 5-TCTTCCTCATCTTCTTGCTCTT-3'; p53, F 5-TGGAGGAGTCACAGTCGGA-3' and p53, R 5-CCATAG TTGCCCTGGTAAGTT-3'; GAPDH, F 5-CCTGGAAGA TGGTGATGGG-3' and GAPDH, R 5-GAAGGTCGGAGT CAACGGAT-3'.

Western blot analysis. Proteins were extracted from the treated cells using a protein isolation kit (cat. no. 28-9425-44; ReadyPrep; GE Healthcare Life Sciences) and the protein levels were quantified using a bicinchoninic acid protein assay kit. The protein $(25 \mu \mathrm{g} /$ lane) was ran on sodium-dodecyl sulfate-polyacrylamide gels (10\%) and then transferred onto nitrocellulose membranes. The membranes were blocked with $5 \%$ skim milk for $2 \mathrm{~h}$ at room temperature. The following

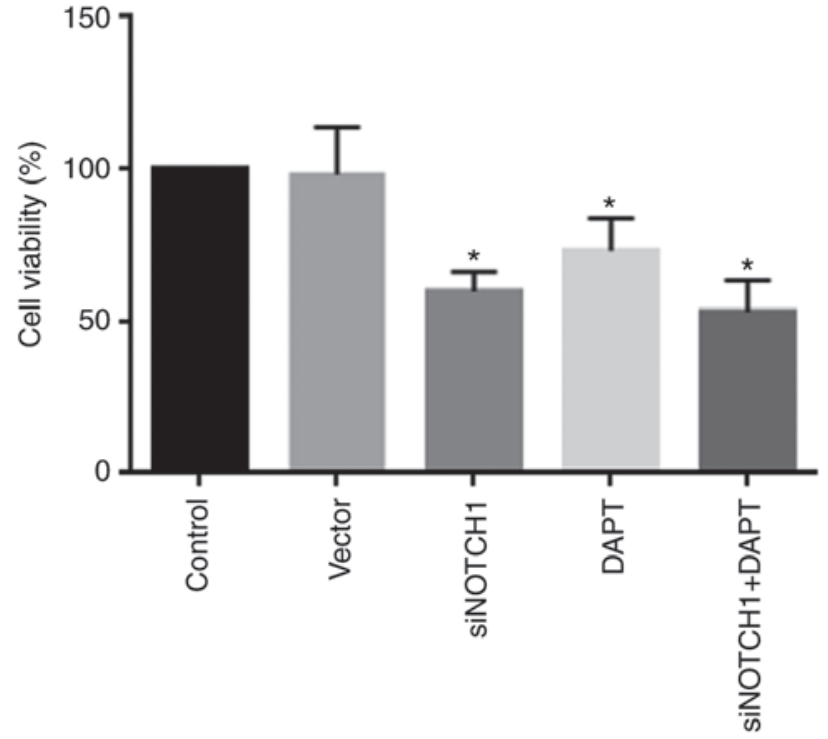

Figure 1. Notch1 inhibition reduces the cell viability of bone marrow mesenchymal stem cells. ${ }^{*} \mathrm{P}<0.05$ vs. control (one-way ANOVA). si, small interfering RNA.

primary antibodies were applied for overnight incubation at $4^{\circ} \mathrm{C}$ : Anti-TGF- $\beta 1$ (cat. no. ab92486), anti-c-Myc (cat. no. ab39688), anti-p53 (cat. no. ab131442), anti-Notch1 (cat. no. ab65297; all 1:1,000; Abcam) and anti-GAPDH (cat. no. TA-08; 1:2,000; OriGene Technologies, Inc.). Following washing with PBST (0.2\% Tween-20), the membranes were incubated with a secondary antibody (cat. no. ab131368; 1:100; Abcam) for $2 \mathrm{~h}$ at room temperature. An enhanced chemiluminescence kit (cat. no. RJ239676; Thermo Fisher Scientific, Inc.) was used and applied to the membrane prior to visualization with ChemiDoc $^{\mathrm{TM}}$ XRS (Bio-Rad Laboratories, Inc.). Densitometry was performed using Quantity One v1.4.6 (Bio-Rad Laboratories, Inc.).

Alizarin red S staining. Osteogenesis was induced using osteogenic differentiation medium (cat. no. MUCMX-90021, Cyagen Biosciences, Inc.) $24 \mathrm{~h}$ following transfection with Notch1 siRNA or treatment with $\gamma$-secretase inhibitor. Osteogenesis was visualized with alizarin red staining at 14 and 21 days. Following the removal of medium, 1X PBS (pH 7.2, without calcium or magnesium) was used to the wash cells, which were then fixed using $4 \%$ polyformaldehyde for $15 \mathrm{~min}$ at room temperature. Alizarin red dye was added for staining of the cells at $37^{\circ} \mathrm{C}$ for $60 \mathrm{~min}$. Images were subsequently captured under light microscopy. Grey intensity was analyzed using ImageProPlus 6.0 (National Institutes of Health). Four fields in each section were analyzed. The intensity was normalized to that in the control group.

Measurement of alkaline phosphatase (AKP) activity. AKP activity was detected 21 days following the induction of osteogenesis using an AKP assay kit according to the manufacturer's instructions (cat. no. A059-2, Nanjing Jiancheng Bioengineering Institute). The AKP content was determined according to the following formula: AKP activity in culture medium $(\mathrm{KU} / 100 \mathrm{ml})=(\mathrm{OD}$ value-Blank OD value $) /(\mathrm{OD}$ 
A
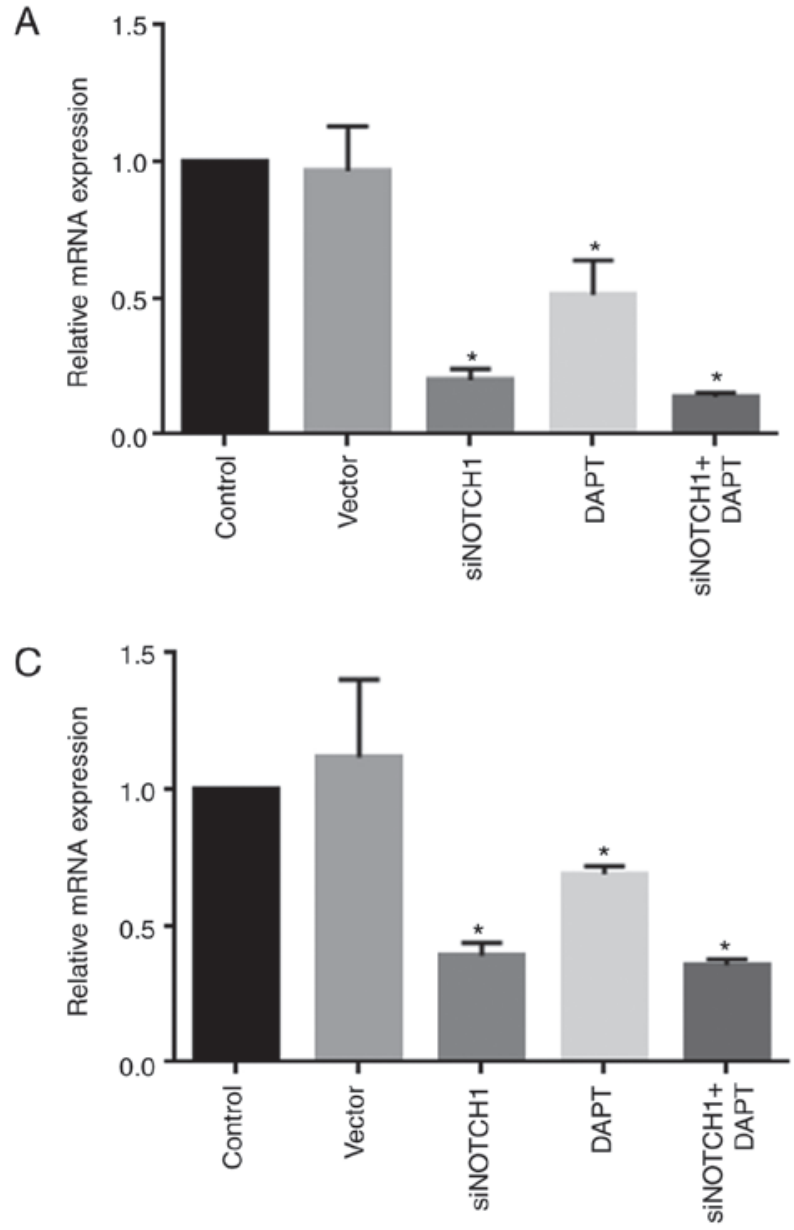

B
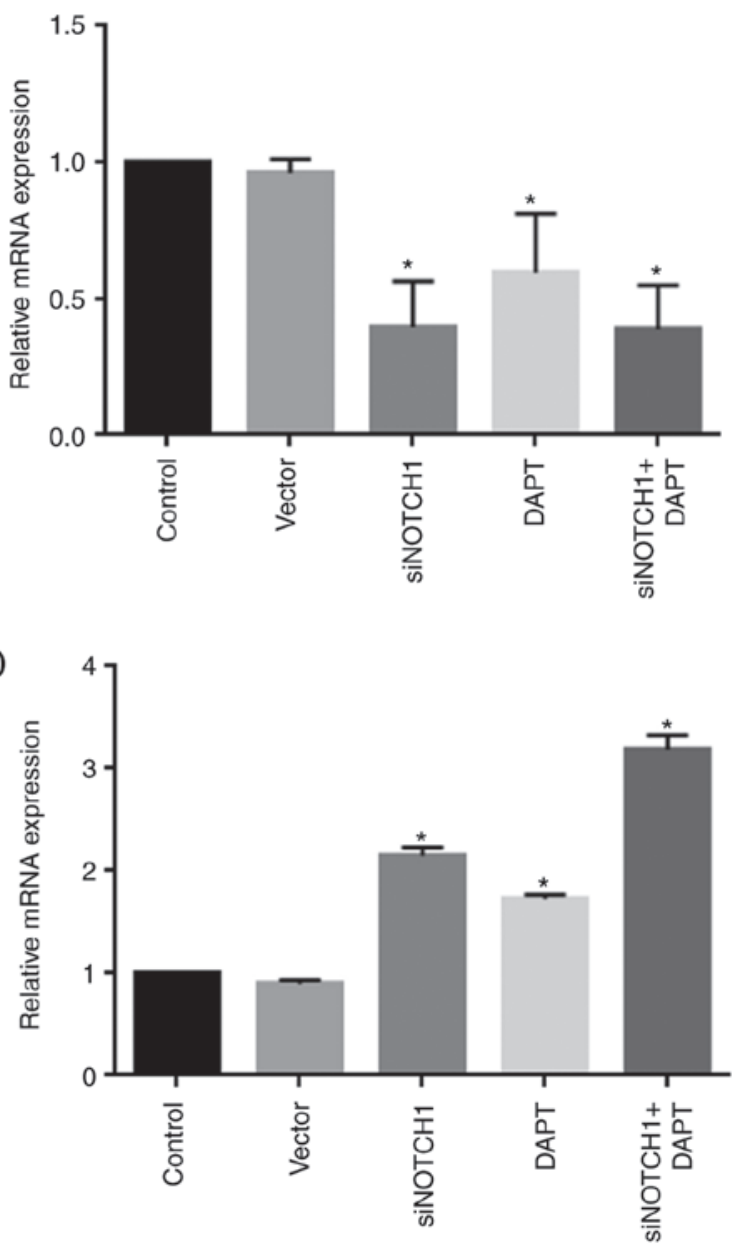

Figure 2. Notch1 inhibition reduces the expression of Notch1, TGF- $\beta 1$ and c-Myc, and promotes the expression of p53 at the mRNA level. (A) Notch1; (B) TGF- $\beta 1$; (C) c-Myc; (D) p53. In each group, there were six repeats. " $\mathrm{P}<0.05$ vs. control (one-way ANOVA). TGF- $\beta 1$, transforming growth factor- $\beta 1$; si, small interfering RNA.

value-Blank OD value) $\mathrm{x}$ phenol standard concentration $(0.02 \mathrm{mg} / \mathrm{ml}) \times 100 \mathrm{ml} \times$ sample dilution prior to determination.

Statistical analysis. Data are presented as the mean \pm SEM. Statistical significance was assessed by one-way ANOVA with Newman-Keuls post-test (SPSS 17.0; SPSS, Inc.). P $<0.05$ was considered to indicate a statistically significant difference.

\section{Results}

Notch1 inhibition reduces BMSC viability. As shown in Fig. 1, siRNA-Notch1 and $\gamma$-secretase inhibitor treatment significantly reduced MSC viability compared with that in the control $(\mathrm{P}<0.05)$. Of note, combined siRNA-Notch1 and $\gamma$-secretase inhibitor treatment did not reduce cell viability to a greater extent than single siRNA-Notch1 or $\gamma$-secretase inhibitor treatment, indicating the specific effect of Notch1 inhibition by siRNA-Notch1 or the $\gamma$-secretase inhibitor.

Notchl inhibition reduces the expression of Notchl, TGF- $\beta 1$ and $c-M y c$, and promotes the expression of $p 53$. As shown in Fig. 2A-D, treatment with siRNA Notch1 and the $\gamma$-secretase inhibitor significantly reduced the expression of Notch1, TGF- $\beta 1$ and c-Myc, and promoted the expression of p53 at the
mRNA level, respectively, compared with levels in the control $(\mathrm{P}<0.05)$. Combined treatment with siRNA-Notch1 and the $\gamma$-secretase inhibitor did not alter gene expression to a greater extent than single siRNA Notch 1 or $\gamma$-secretase inhibitor treatment.

Consistently, siRNA Notch1 and $\gamma$-secretase inhibitor treatment significantly reduced the expression of Notch1, TGF- $\beta 1$ and c-Myc, and promoted the expression of p53 at the protein level, compared with levels in the control $(\mathrm{P}<0.05)$. Combined siRNA-Notch1 and $\gamma$-secretase inhibitor treatment did not alter gene expression to a greater extent than single siRNA-Notch1 or $\gamma$-secretase inhibitor treatment (Fig. 3A-E).

Notch1 inhibition accelerates osteogenic differentiation. As shown in Fig. 4A, siRNA Notch1 and $\gamma$-secretase inhibitor treatment significantly accelerated osteogenic differentiation at days 14 and 21, respectively, compared with that in the control group $(\mathrm{P}<0.05)$. Combined siRNA-Notch1 and $\gamma$-secretase inhibitor treatment did not promote osteogenic differentiation to a greater extent than single siRNA-Notch1 or $\gamma$-secretase inhibitor treatment.

Notch1 inhibition promotes AKP activity. As shown in Fig. 5, siRNA-Notch1 and $\gamma$-secretase inhibitor treatment 

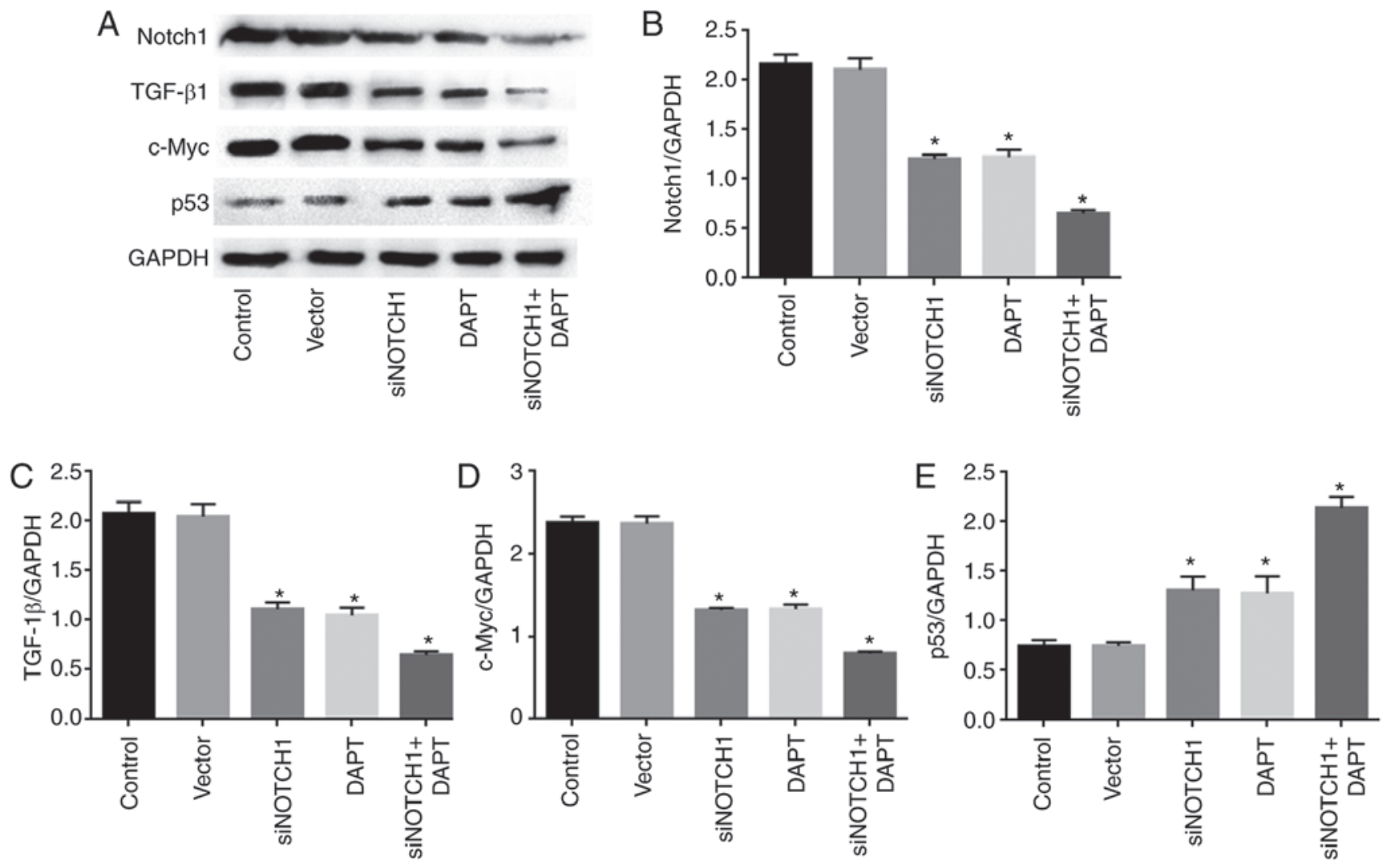

Figure 3. Notch1 inhibition reduces the expression of Notch1, TGF- $\beta 1$ and c-Myc, and promotes the expression of p53 at the protein level. (A) Representative blots; (B) Notch1; (C) TGF- $\beta 1$; (D) c-Myc; (E) p53. In each group, there were six repeats. "P $<0.05$ vs. control (one-way ANOVA). TGF- $\beta 1$, transforming growth factor- $\beta 1$; si, small interfering RNA.

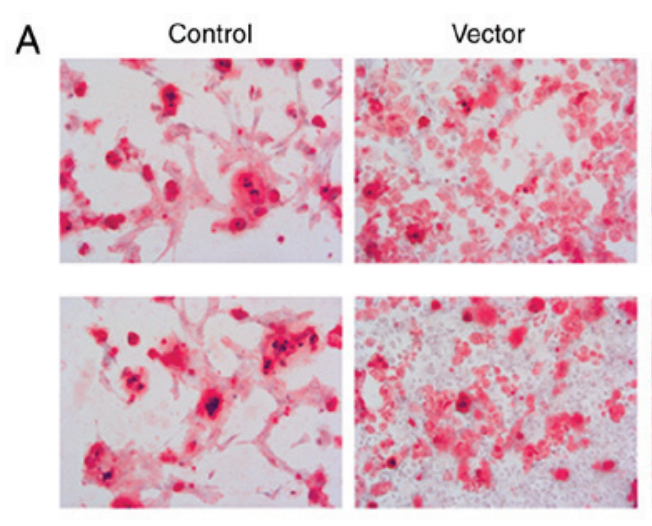

B

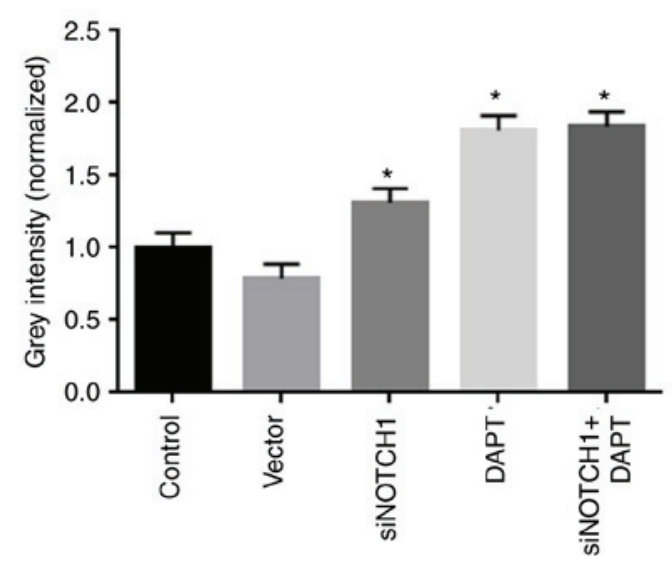

SiNOTCH1

DAPT siNOTCH1+DAPT
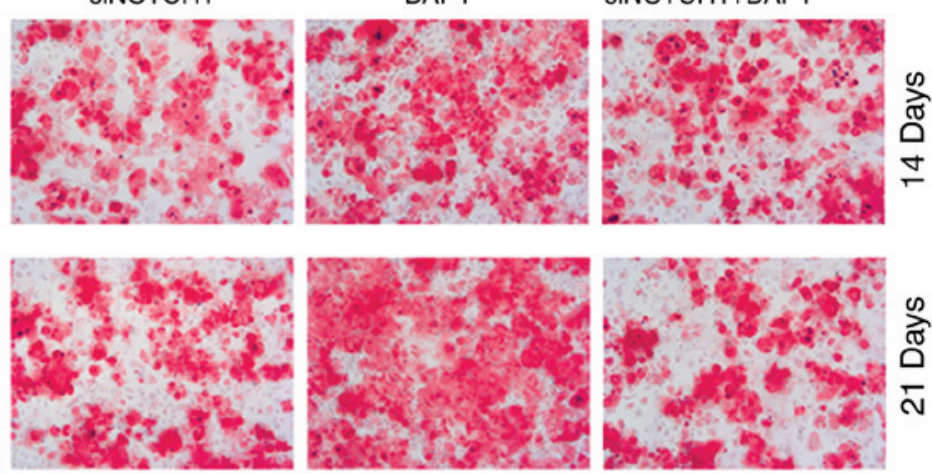

C

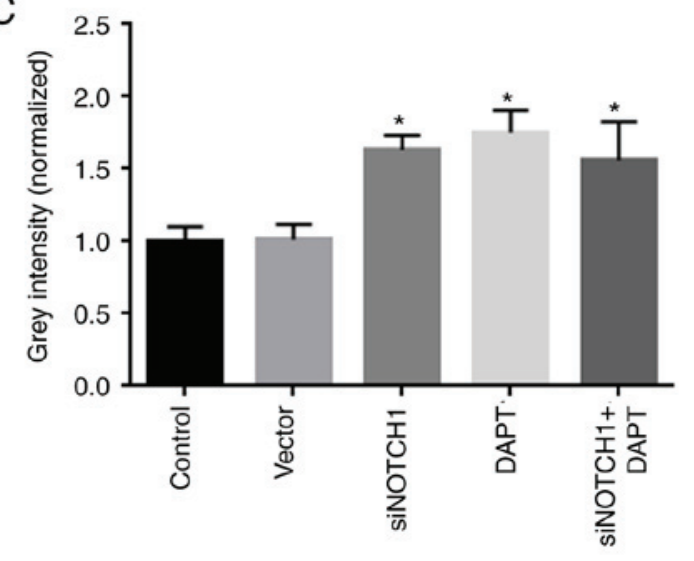

Figure 4. Notch1 inhibition improves osteogenic differentiation. (A) Representative images (magnification, x200). (B) Grey value of cells on day 14. (C) Grey value of cells on day 21. In each group, there were six repeats. "P<0.05 vs. control (one-way ANOVA). si, small interfering RNA. 


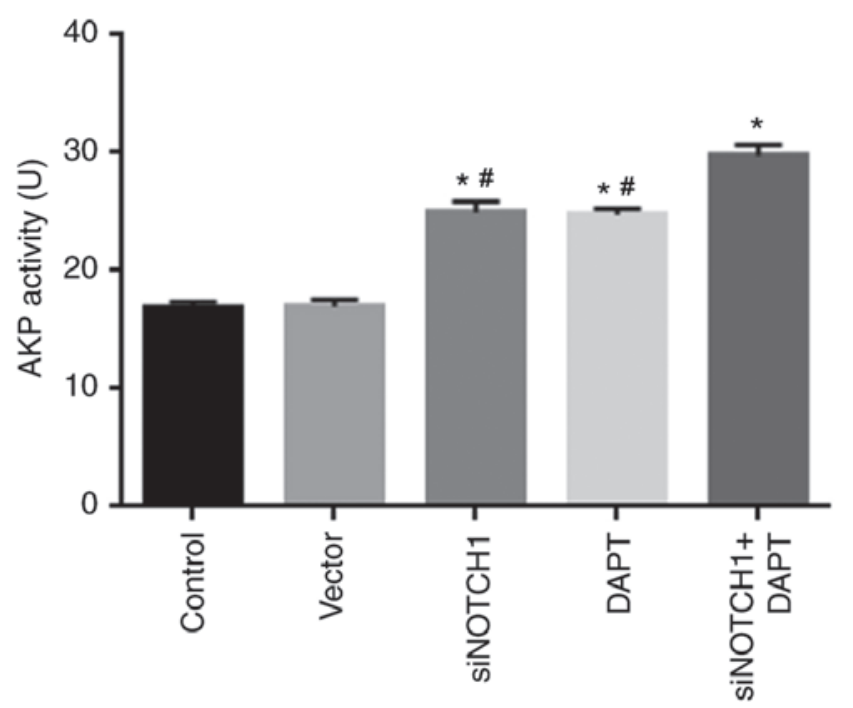

Figure 5. Notch1 inhibition promotes AKP activity. In each group, there were six repeats. ${ }^{*} \mathrm{P}<0.05$ vs. control, ${ }^{\#} \mathrm{P}<0.05$ vs. siNOTCH1+DAPT (one-way ANOVA). AKP, alkaline phosphatase; si, small interfering RNA.

significantly promoted AKP activity, respectively, compared with that in the control $(\mathrm{P}<0.05)$. Combined siRNA-Notch1 and $\gamma$-secretase inhibitor treatment further promoted osteogenic differentiation compared with that following treatment with either siRNA-Notch1 or $\gamma$-secretase inhibitor treatment alone.

\section{Discussion}

The present study demonstrated that Notch1 inhibition by siRNA or a specific inhibitor reduced MSC viability, as evidenced by the decreased expression of TGF- $\beta 1$ and c-Myc and increased expression of p53, but it promoted osteogenic differentiation.

Osteosarcoma is a condition likely arising from cancerous stem cells. Gibbs et al (16) first isolated stem cell-like tumor cells from an osteosarcoma. These cells were found to express embryonic stem cell markers (Oct 3/4 and Nanog) and surface molecules of MSCs (Stro-1, CD105 and CD44). Osteosarcoma stem cells are considered to be homologous to MSCs. Based on the common pathological manifestations of osteosarcoma, in addition to previous findings of malignant MSCs and osteoid cells $(17,18)$, it has been suggested that the condition likely originates from adult stem cells (16-18). In addition, MSCs and tumor stem cells have several similar characteristics, including the capacity of unlimited proliferation and differentiation, a common molecular diffusion mechanism, and telomerase activity. The microenvironment is important for MSC differentiation and regulation. These cells are also involved in the formation and maintenance of the microenvironment, which is vital for effective networking between tumor cells. MSC homing to the tumor mass also promotes tumor growth and metastasis $(19,20)$. For the aforementioned reasons, MSCs can be considered as potential cancer therapy targets.

The Notch signaling pathway is a conserved signaling mechanism that is widely distributed among most multicellular organisms. This pathway has been reported to exert a major influence on the proliferation of mouse embryonic fibroblasts in the process of bone morphogenetic protein-9-induced osteogenic differentiation (21). In a previous study, the overexpression of Notch1 improved the proliferation, migration and survival of MSCs induced by cigarette smoke extract (22). However, the effects of Notch1 on the proliferation of MSCs under normal conditions were not evaluated. In the present study, it was demonstrated that Notch1 inhibition reduced BMSC proliferation, suggesting that Notch1 is a potential oncogene for BMSC transformation into osteosarcoma.

TGF- $\beta 1$, a multifunctional cytokine $(23,24)$, is involved in the differentiation, survival and growth of a variety of cell types. TGF- $\beta 1$ promotes the differentiation of bone MSCs in vitro (25) and has been reported to serve an important role in the development of the mouse myocardium via the induction of mouse embryonic stem cell differentiation into cardiac myocytes (26). This cytokine is also involved in SMAD2 and SMAD3 signaling pathways and the induction of neural crest stem cell differentiation into functional smooth muscle cells (27). TGF- $\beta 1$ also induces cardiomyocyte hypertrophy via SMAD4/SMAD3 protein complex interactions and the alteration of downstream gene functions (28). The present study found that Notch1 inhibition reduced the expression of TGF- $\beta 1$ at the mRNA and protein levels. As TGF- $\beta 1$ can promote tumorigenesis in this setting (29-31), a reduction in TGF- $\beta 1$ by Notch 1 inhibition further underscored the oncogenic activity of Notch1.

c-Myc is one of the three closely related transcription factor family genes, and Myc genes are upregulated in various types of human cancer. The upregulated expression of c-Myc promotes cell proliferation and cell growth, the synthesis of ribosomes and proteins, energy production (i.e. glycolysis) and anabolism $(32,33)$. The present study found that siRNA-Notch1 and $\gamma$-secretase inhibitor treatment reduced the expression of TGF- $\beta 1$ and $c-M y c$ and increased the expression of p53. Excessive expression of c-Myc reduces the effect of growth factors and promotes cell proliferation. It also downregulates c-Myc and may arrest cells at the G1 phase, thus slowing the rate of cell growth (34).

Once osteoblasts are differentiated, they secrete extracellular matrix proteins and control the mineralization of bone matrix (35). AKP, characteristically expressed in osteoblasts, serves a key role in calcification in vitro. In an alkaline buffer, AKP catalyzes the hydrolysis of a-monophosphate to produce $\alpha$-naphthol, which is coupled to a stable diazonium salt to produce insoluble azo dyes. In the present study, the results of alizarin red staining and AKP activity assays indicated that the inhibition of Notch1 reduced BMSC proliferation and promoted osteogenic differentiation. These results indicate that the Notch signaling pathway was inhibited during BMSC differentiation, suggesting that Notch signaling has a negative effect on BMSC osteogenic differentiation (35). In the present study, Notch1 inhibition was performed by knocking out Notch1 at the gene level and by using $\gamma$-secretase inhibitors. No difference between the $\gamma$-secretase inhibitor and siRNA Notch1 was observed regarding cell viability and the molecular changes of different proteins. In addition, the combination of $\gamma$-secretase inhibitor and siRNA Notch1 did not further promote the effects. These data implicate the specific effects of Notch1 inhibition by siRNA-Notch1 or the $\gamma$-secretase inhibitor. 
There were several limitations in the present study. Firstly, a CCK assay was used to detect cell viability, which explained cell proliferation to an extent. However, the tumorigenesis of BMSCs can be assessed by other methods, such as adding proliferating cell nuclear antigen as an indicator. Secondly, further experiments are required to confirm that the development of osteosarcoma is related to Notch1. Whether Notch1 activation correlates with the development of osteosarcoma could be confirmed in the future. Finally, in vivo data of tumorigenesis may provide further evidence.

In conclusion, Notch1 inhibition reduced BMSC proliferation and promoted the osteogenic differentiation of this cell type. The results of the present study outline a novel potential therapeutic target in the prevention of BMSC tumorigenesis and provides a foundation for future clinical applications.

\section{Acknowledgements}

Not applicable.

\section{Funding}

This study was supported by NSFC (81000676, 81660364), the Special Research Fund for Doctoral Disciplines (grant no. 20093601120005) and Jiangxi Natural Science Foundation (grant no. 2012ZBAB205004).

\section{Availability of data and materials}

The datasets used and/or analyzed during the current study are available from the corresponding author on reasonable request.

\section{Authors' contributions}

YH and LZ performed the experiments and analyzed the data. LZ designed the study and wrote the manuscript.

\section{Ethics approval and consent to participate}

Not applicable.

\section{Patient consent for publication}

Not applicable.

\section{Competing interests}

The authors declare that they have no competing interests.

\section{References}

1. Ren T, Piperdi S, Koirala P, Park A, Zhang W, Ivenitsky D, Zhang Y, Villanueva-Siles E, Hawkins DS, Roth M and Gorlick R: CD49b inhibits osteogenic differentiation and plays an important role in osteosarcoma progression. Oncotarget 8: 87848-87859, 2017.

2. Nombela-Arrieta C, Ritz J and Silberstein LE: The elusive nature and function of mesenchymal stem cells. Nat Rev Mol Cell Biol 12: 126-131, 2011.
3. Williams AR and Hare JM: Mesenchymal stem cells: Biology, pathophysiology, translational findings, and therapeutic implications for cardiac disease. Circ Res 109: 923-940, 2011.

4. Morancho A, Ma F, Barcelo V, Giralt D, Montaner J and Rosell A: Impaired vascular remodeling after endothelial progenitor cell transplantation in MMP9-deficient mice suffering cortical cerebral ischemia. J Cereb Blood Flow Metab 35: 1547-1551, 2015.

5. Wallner C, Abraham S, Wagner JM, Harati K, Ismer B, Kessler L, Zöllner H, Lehnhardt M and Behr B: Local application of isogenic adipose-derived stem cells restores bone healing capacity in a type 2 diabetes model. Stem Cell Transl Med 5: 836-844, 2016.

6. Gupta PK, Chullikana A, Parakh R, Desai S, Das A, Gottipamula S, Krishnamurthy S, Anthony N, Pherwani A and Majumdar AS: A double blind randomized placebo controlled phase I/II study assessing the safety and efficacy of allogeneic bone marrow derived mesenchymal stem cell in critical limb ischemia. J Transl Med 11: 143, 2013.

7. Lara-Hernandez R, Lozano-Vilardell P, Blanes P, Torreguitart-Mirada N, Galmes A and Besalduch J: Safety and efficacy of therapeutic angiogenesis as a novel treatment in patients with critical limb ischemia. Ann Vasc Surg 24: 287-294, 2010.

8. He Y, Zhu W, Shin MH, Gary J, Liu C, Dubois W, Hoover SB, Jiang S, Marrogi E, Mock B, et al: cFOS-SOX9 axis reprograms bone marrow-derived mesenchymal stem cells into chondroblastic osteosarcoma. Stem Cell Rep 8: 1630-1644, 2017.

9. Yuan TM and Yu HM: Notch signaling: Key role in intrauterine infection/inflammation, embryonic development, and white matter damage? J Neurosci Res 88: 461-468, 2010.

10. Reddy BV, Rauskolb C and Irvine KD: Influence of fat-hippo and notch signaling on the proliferation and differentiation of Drosophila optic neuroepithelia. Development 137: 2397-2408, 2010.

11. Bray SJ: Notch signalling in context. Nat Rev Mol Cell Biol 17: 722-735, 2016.

12. Colombo M, Galletti S, Garavelli S, Platonova N, Paoli A, Basile A, Taiana E, Neri A and Chiaramonte R: Notch signaling deregulation in multiple myeloma: A rational molecular target. Oncotarget 6: 26826-26840,2015.

13. Cristofaro B and Emanueli C: Possible novel targets for therapeutic angiogenesis. Curr Opin Pharmacol 9: 102-108, 2009.

14. Liang T, Zhu L, Gao W, Gong M, Ren J, Yao H, Wang K and Shi D: Coculture of endothelial progenitor cells and mesenchymal stem cells enhanced their proliferation and angiogenesis through PDGF and Notch signaling. FEBS Open Bio 7: 1722-1736, 2017.

15. Livak KJ and Schmittgen TD: Analysis of relative gene expression data using real-time quantitative PCR and the 2(-Delta Delta C(T)) method. Methods 25: 402-408, 2001.

16. Gibbs C, Kukekov VG, Reith JD, Tchigrinova O, Suslov ON, Scott EW, Ghivizzani SC, Ignatova TN and Steindler DA: Stem-like cells in bone sarcomas: Implications for tumorigenesis. Neoplasia 7: 967-976, 2005.

17. Berman SD, Calo E, Landman AS, Danielian PS, Miller ES, West JC, Fonhoue BD, Caron A, Bronson R, Bouxsein ML, et al: Metastatic osteosarcoma induced by inactivation of $\mathrm{Rb}$ and p53 in the osteoblast lineage. Proc Natl Acad Sci USA 105: 11851-11856, 2008.

18. Tataria M, Quarto N, Longaker MT and Sylvester KG: Absence of the p53 tumor suppressor gene promotes osteogenesis in mesenchymal stem cells. J Pediatr Surg 41: 624-632, 2006.

19. Sun Z, Wang S and Zhao RC: The roles of mesenchymal stem cells in tumor inflammatory microenvironment. J Hematol Oncol 7: 14, 2014.

20. Hill BS, Pelagalli A, Passaro N and Zannetti A: Tumor-educated mesenchymal stem cells promote pro-metastatic phenotype. Oncotarget 8: 73296-73311, 2017.

21. Cao J, Wei Y, Lian J, Yang L, Zhang X, Xie J, Liu Q, Luo J, He B and Tang M: Notch signaling pathway promotes osteogenic differentiation of mesenchymal stem cells by enhancing BMP9/Smad signaling. Int J Mol Med 40: 378-388, 2017.

22. Cheng Y, Gu W, Zhang G, Li X and Guo X: Activation of Notch1 signaling alleviates dysfunction of bone marrow-derived mesenchymal stem cells induced by cigarette smoke extract. Int J Chron Obstruct Pulmon Dis 12: 3133-3147, 2017.

23. Li TS, Hayashi M, Ito H, Furutani A, Murata T, Matsuzaki M and Hamano K: Regeneration of infarcted myocardium by intramyocardial implantation of ex vivo transforming growth factor-beta-preprogrammed bone marrow stem cells. Circulation 111: 2438-2445, 2005. 
24. Li Y, Powell S, Brunette E, Lebkowski J and Mandalam R: Expansion of human embryonic stem cells in defined serum-free medium devoid of animal-derived products. Biotechnol Bioeng 91: 688-698, 2005.

25. Gwak SJ, Bhang SH, Yang HS, Kim SS, Lee DH, Lee SH and Kim BS: In vitro cardiomyogenic differentiation of adipose-derived stromal cells using transforming growth factor-beta1. Cell Biochem Funct 27: 148-154, 2009.

26. Akhurst RJ, Lehnert SA, Faissner A and Duffie E: TGF beta in murine morphogenetic processes: The early embryo and cardiogenesis. Development 108: 645-656, 1990.

27. Chen S and Lechleider RJ: Transforming growth factor-betainduced differentiation of smooth muscle from a neural crest stem cell line. Circ Res 94: 1195-1202, 2004.

28. Mueller MB, Fischer M, Zellner J, Berner A, Dienstknecht T, Prantl L, Kujat R, Nerlich M, Tuan RS and Angele P: Hypertrophy in mesenchymal stem cell chondrogenesis: Effect of TGF-beta isoforms and chondrogenic conditioning. Cells Tissues Organs 192: $158-166,2010$.

29. Hu ML, Wang XY and Chen WM: TGF- $\beta 1$ upregulates the expression of lncRNA UCA1 and its downstream HXK2 to promote the growth of hepatocellular carcinoma. Eur Rev Med Pharmacol Sci 22: 4846-4854, 2018.

30. Viloria ME, Bravo J, Carrero Y and Mosquera JA: In situ expressions of protein $\left.16\left(\mathrm{p} 16^{\mathrm{CDKN} 2 \mathrm{~A}}\right)\right)$ and transforming growth factor beta-1 in patients with cervical intraepithelial neoplasia and cervical cancer. Eur J Obstet Gynecol Reprod Biol 228: 303-307, 2018.
31. Cui M, Chang Y, Du W,Liu S, Qi J,Luo R and Luo S: Upregulation of IncRNA-ATB by transforming growth factor beta1 (TGF- $\beta 1$ ) promotes migration and invasion of papillary thyroid carcinoma cells. Med Sci Monit 24: 5152-5158, 2018.

32. Gallant P: Myc/Max/Mad in invertebrates: The evolution of the Max network. Curr Top Microbiol Immunol 302: 235-253, 2006.

33. Lin TP, Li J, Li Q, Li X, Liu C, Zeng N, Huang JM, Chu GC, Lin $\mathrm{CH}$, Zhau HE, et al: R1 Regulates prostate tumor growth and progression by transcriptional suppression of the E3 Ligase HUWE1 to Stabilize c-Myc. Mol Cancer Res 16: 1940-1951, 2018.

34. Zhou X, Wen Y, Tian Y, He M, Ke X, Huang Z, He Y, Liu L, Scharf A, Lu M, et al: Hsp90alpha-dependent B-Claf-1 promotes hepatocellular carcinoma proliferation by regulating c-MYC mRNA stability. Hepatology, 2018.

35. Zanotti S, Smerdel-Ramoya A, Stadmeyer L, Durant D, Radtke F and Canalis E: Notch inhibits osteoblast differentiation and causes osteopenia. Endocrinology 149: 3890-3899, 2008. 